\section{Effects of Storage Period on Growth and Development in Five Achimenes Cultivars}

\author{
Chad T. Miller ${ }^{1,3}$ and Mark P. Bridgen ${ }^{2}$
}

AdDitional Index words. dormancy, rhizomes, magic plant, Gesneriaceae, pupation, floriculture

SuMmARY. The dormancy mechanism in achimenes (Achimenes hybrids) has not been thoroughly characterized. Rhizomes of five recently developed achimenes cultivars were stored for $0,4,8,12$, or 16 weeks at $68^{\circ} \mathrm{F}$. Cultivar A09 demonstrated a strong decrease in the time to root after 4 weeks of storage, rooting after 13 weeks postplanting. The rooting response for cultivars A16, A21, and A22 was significantly less than cultivar A09; they developed roots between 2.6 and 7.6 weeks after 4 weeks of storage. Rhizomes stored longer than 8 weeks resulted in decreased rooting responses for all cultivars. Shoot emergence was delayed in all cultivars with cultivars without any storage period; cultivars A09, A16, and A23 exhibited a stronger delay than other cultivars. After 4 weeks of storage, the number of weeks to shoot development decreased for all cultivars and after each additional 4-week storage period, the number of weeks to shoot development decreased or remained the same. After 16 weeks of storage, shoots developed in less than 4 weeks for all cultivars. Pupation occurred in four of five cultivars on rhizomes given no storage or with only 4 weeks of storage. The results obtained suggest that the dormancy period of some newer achimenes cultivars is abbreviated in comparison with older cultivars.

A chimenes, also commonly referred to as hot water plant, magic plant, or monkey facedpansy, is a member of the Gesneriaceae. The genus is comprised of 25 species native to subtropical forest regions of Central America and northern South America (Brickell and Zuk, 1996). Achimenes have been cultivated since the late 1700 s, upon first introduction to England (Jungbauer, 1977). Popularity has waned and surged, largely following breeding efforts undertaken in the 1940s in The Netherlands, Germany, and the United States (Vlahos, 1991). Recently renewed breeding efforts have led to increased interest in achimenes.

Achimenes flower profusely through the summer into the fall, ranging in color from white, pink, purple, yellow, and red. Achimenes are well suited for use as pot plants, in mixed containers, and in hanging baskets (De Hertogh and Le Nard, 1993; Wilkins, 2005), with the potential for use as a bedding plant. Despite their great ornamental qualities, greenhouse

We would like to thank Oglevee, Ltd. (Connellsville, PA) for supplying achimenes rhizomes to conduct the experiments and funding from the Post-Schenkel Foundation and the New York State Flower Industries.

${ }^{1}$ Department of Horticulture, Cornell University, 159 Plant Science Building, Ithaca, NY 14850

${ }^{2}$ Professor, mpb27@cornell.edu.

${ }^{3}$ Corresponding author. E-mail: ctm25@cornell.edu. production of achimenes has been limited due to a required dormancy period.

The dormancy initiation and release mechanism(s) in achimenes are poorly understood. Even under optimal growth conditions, the aerial vegetation begins to senesce, and for unknown reasons, the plant enters a dormant phase (Lyon, 1967). It also has been reported that if achimenes are not kept evenly moist, premature dormancy can occur if plants are allowed to dry out excessively (Brickell and Zuk, 1996; Larson, 1992; Marvinny, 1967; Wiles, 1988). When the foliage begins to senesce, rhizomes that have developed on underground stolons become dormant or inactive, and, like some other geophytes, will not resume growth until the necessary dormant period has been achieved. Dormancy of achimenes has been reported to last between 12 and 20 weeks, depending on the cultivar (Wiles, 1988). A greater understanding and ability to manipulate the dormancy in achimenes would allow for increased greenhouse production and increase the crop diversity in the floriculture industry. The objective of this study was to evaluate the dormancy characteristics of five recently developed achimenes cultivars and its effect on the subsequent number of weeks to root and shoot emergence.

\section{Materials and methods}

Five new, unnamed achimenes cultivars, A09, A16, A21, A22, and A23 from a commercial supplier (Oglevee, Connellsville, PA) were used to investigate dormancy characteristics. Rhizomes of each cultivar were collected from senescing plants in June 2003. The freshly harvested rhizomes were washed with tap water and air dried overnight. The following day, four 6-inch-diameter pots each containing three rhizomes of each cultivar were planted using commercial growing medium (Metro Mix 360; Scott's, Marysville, $\mathrm{OH})$. Another 50 freshly harvested rhizomes of each cultivar were randomly selected and divided into five groups of 10. Each group of 10 was then subdivided in half and stored in plastic sandwich bags in light (16 h of continuous illumination at $\left.185 \mu \mathrm{mol} \cdot \mathrm{m}^{-2} \cdot \mathrm{s}^{-1}\right)$ or dark $(24 \mathrm{~h})$ conditions at $68{ }^{\circ} \mathrm{F}$ until planting. Rhizome storage and culturing were conducted in growth chambers (Percival, Perry, IA or Environmental Growth Chambers, Chagrin Falls, $\mathrm{OH})$. The environmental parameters remained constant during storage.

Bags of rhizomes of each cultivar were removed monthly, for 5 months, from the light and dark storage treatments and were randomly planted 1 inch deep horizontally in 50-cell propagation plug trays containing Metro Mix 360. Cell trays were placed in the growth chamber at $68^{\circ} \mathrm{F}$ with $16 \mathrm{~h}$ of fluorescent and incandescent lighting at $185 \mu \mathrm{mol} \cdot \mathrm{m}^{-2} \cdot \mathrm{s}^{-1}$ and were watered as needed.

The cell trays were removed weekly from the growth chamber, and observations were made on rhizome growth and development. Rhizomes were gently lifted from the media and carefully replanted after observations

\begin{tabular}{llll}
\hline $\begin{array}{l}\text { Units } \\
\text { To convert U.S. to SI, } \\
\text { multiply by }\end{array}$ & U.S. unit & SI unit & $\begin{array}{l}\text { To convert SI to U.S., } \\
\text { multiply by }\end{array}$ \\
\hline 2.54 & inch(es) & ${ }^{\mathrm{cm}}$ & 0.3937 \\
$\left({ }^{\circ} \mathrm{F}-32\right) \div 1.8$ & ${ }^{\circ} \mathrm{F}$ & ${ }^{\circ} \mathrm{C}$ & $\left(1.8 \times{ }^{\circ} \mathrm{C}\right)+32$
\end{tabular}


were made. Data recorded included: the number of weeks to root from planting, in which rooting was characterized when a rhizome had developed three or more roots of $3 \mathrm{~mm}$ or more in length; the number of weeks to shoot emergence, defined as the period of time when the shoot apex was visible above the media surface; and pupation, which was recorded when new, creamcolored dormant corm or "pupa" tissue developed at the apex of the mother rhizome (Fig. 1). The independent variables were the number of weeks of storage, light treatments, cultivar, and possible interactions of main effects. The dependent variables, number of weeks to root development and number of weeks to shoot emergence, were normalized by log transformation before an analysis of variance. Mean separation was performed using Tukey's honestly significant difference test at $P \leq 0.05$ (SAS, version 8; SAS Institute, Cary, NC).

\section{Results}

No differences were observed between light- and dark-treated rhizomes (data not shown) on subsequent growth and development of the achimenes cultivars tested and, thus, the two data sets were pooled for further analysis. An interaction occurred between the number of weeks of storage and cultivar on rooting. Rhizomes of most cultivars that received no storage period rooted between 3 and 4 weeks after planting, except for 'A2l' that rooted in 5 weeks (Fig. 2C). After 4 weeks of storage, the time to root was unchanged for cultivars A21, A22, and Al6; however, the time to root drastically increased, doubling and quadrupling in cultivars A23 and A09, respectively (Fig. 2, E and A). After 8 weeks of storage, the rooting time in 'A09' significantly decreased (Fig. $2 \mathrm{~A}$ ), while rooting time remained unchanged for the remaining cultivars. Time to root decreased for all cultivars after 12 weeks of storage and further decreased after 16 weeks of storage.
All cultivars rooted in less than 4 weeks after 12 weeks of storage.

There was also an interaction with the number of storage weeks and cultivar on the number of weeks to shoot emergence. Shoot emergence was delayed for all cultivars that received 0 weeks of storage when compared with rhizomes that received some storage (Fig. 2, A-E). Shoot emergence for 'A09' was delayed the longest (Fig. 2A); it developed shoots after more than 26 weeks without storage, while 'A22' rhizomes given 0 weeks of storage produced shoots after only 9 weeks (Fig. 2D). The number of weeks to shoot emergence decreased for all cultivars after 4 weeks of storage (Fig. 2, A-E). The number of weeks to shoot emergence did not decrease after 8 weeks of storage for all cultivars except 'A09'. Shoot emergence was 4 weeks or less for all cultivars when rhizomes were stored for 16 weeks (Fig. 2, A-E).

Not all achimenes cultivars pupated in this study. Most pupation occurred in rhizomes that received no storage treatment (Table 1). When freshly harvested rhizomes of cultivars A16, A21, and A23 were planted and grown at $68{ }^{\circ} \mathrm{F}$, over $90 \%$ of the rhizomes pupated, while cultivars A09 and A22 did not pupate. The percentage of pupation in 'A23' decreased after 4 weeks of storage, while pupation increased in 'A09'. No pupation was observed in any cultivar after 8 weeks of storage.

\section{Discussion}

It is well known that different cultivars of a species often exhibit different growth characteristics. The five achimenes cultivars examined in this study show exhibited genotypic differences with regard to duration of rhizome storage. Dormancy is often used to describe the cessation of apparent growth, particularly of the apical meristem, due to external factors such as temperature or daylength (Rees, 1992).

No differences were observed between light and dark treatments

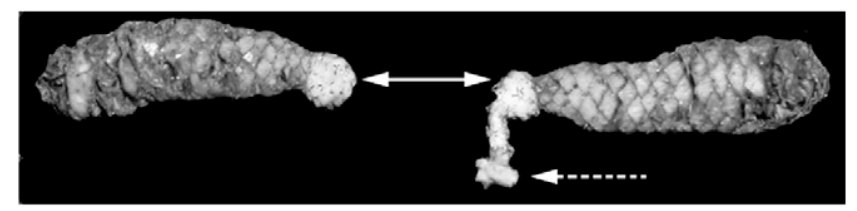

Fig. 1. Pupation on achimenes rhizomes (solid arrow) and shoot development from pupation (dashed arrow). on the growth and development of the achimenes cultivars tested. This is contrary to results previously reported by Vlahos (1985) where, in the cultivar Viola Michelssen, light appeared to have an inhibitory role in breaking of dormancy.

Storage time affected rooting of some achimenes cultivars more than others. Rhizomes of 'A09' planted immediately after harvest with no storage treatment rooted relatively quickly at about 3 weeks, while rhizomes that were planted after receiving 4 weeks of storage had developed strong root dormancy during storage. Similarly, in 'A23' roots developed soon after planting, 4 weeks, without any imposed storage period. After 4 weeks of storage, a similar but less dramatic trend as that of 'A09' was observed in that each subsequent storage treatment after 8 weeks of storage resulted in a decreased time to root. In these two cultivars, rooting ability is likely a case of declining active growth and the rhizomes have not fully entered into a dormant period. The remaining cultivars, particularly A22, showed that there was little change in the amount of time to root, regardless of the amount of storage time.

A more visible indicator of dormancy or lack thereof, is the active growth and development of the apical meristem. Our results provide some evidence that rhizome dormancy exists, similar to that reported (Wiles, 1988). However, some newer achimenes cultivars do not possess as long a dormant period as has been previously reported. This abbreviated dormant period could be a result of hybridization, as many of the newer cultivars, when compared with older cultivars, are different in their growth and development (L. Drewlow, personal communication).

Table 1. Effect of storage duration on percentage of rhizome pupation of five achimenes cultivars.

\begin{tabular}{lrrrrr}
\hline & \multicolumn{5}{c}{ Rhizome pupation (\%) } \\
\cline { 2 - 6 } Cultivar & \multicolumn{1}{c}{$\mathbf{0}$} & $\mathbf{4}$ & $\mathbf{8}$ & $\mathbf{1 2}$ & $\mathbf{1 6}$ \\
\hline A09 & 0 & 40 & 0 & 0 & 0 \\
A16 & 92 & 0 & 0 & 0 & 0 \\
A21 & 92 & 0 & 0 & 0 & 0 \\
A22 & 0 & 0 & 0 & 0 & 0 \\
A23 & 100 & 10 & 0 & 0 & 0 \\
\hline
\end{tabular}

${ }^{\mathrm{z}} \mathrm{n}=10$ rhizomes per cultivar per storage week; except for 0 storage weeks, where $\mathrm{n}=12$. 


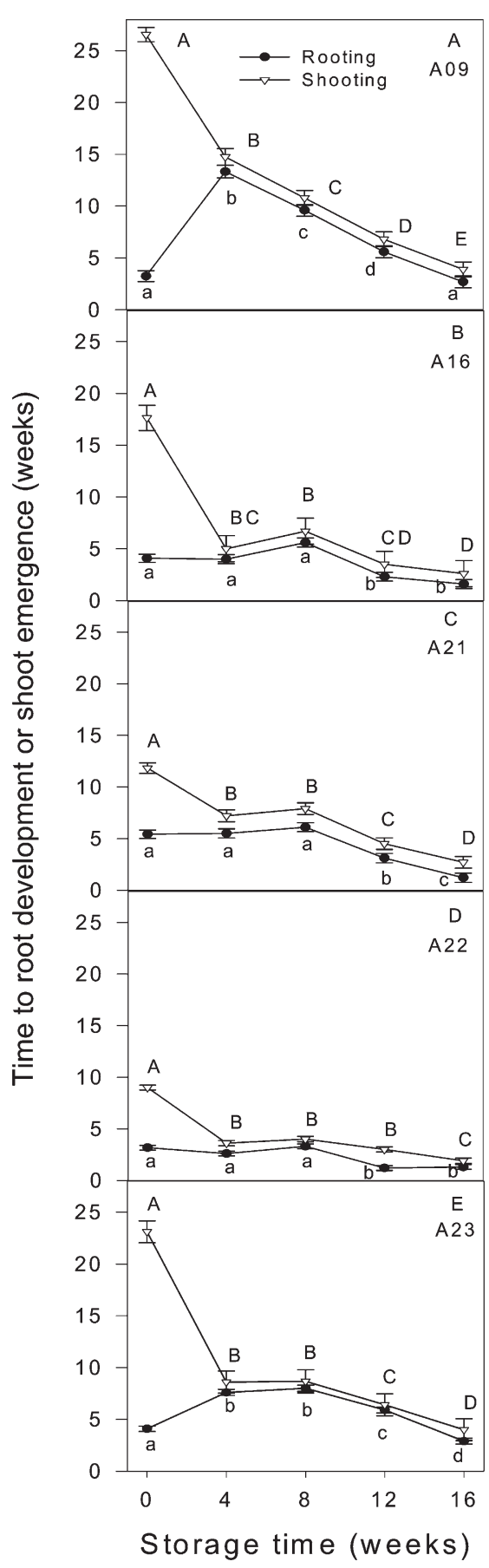

Fig. 2. The effect of storage time on achimenes rhizomes at $68^{\circ} \mathrm{F}\left(20.0^{\circ} \mathrm{C}\right)$ on the number of weeks to root and shoot in five cultivars: A09, A16, A21, A22, and A23. Means followed by different letters are significantly different by Tukey's honestly significant difference test $(P \leq \mathbf{0 . 0 5})$. Means of weeks to root are shown with lowercase letters and the response means of weeks to shoot are shown with uppercase letters. Error bars are \pm 1 SE.

The critical storage period on the number of weeks to shoot emergence for the cultivars tested is at least 4 weeks. When rhizomes of all cultivars did not receive any storage period, the number of weeks to shoot development and emergence was significantly greater, most notably for the cultivars A09 and A23; shoot development for these cultivars only occurred after 5 months after planting. Cultivar A22 exhibited a weaker initial dormancy period; shoots emerged after only 8 weeks of storage. The number of weeks to emerge decreased, although not always significantly, as the number of storage weeks increased. These results were similar to Harbaugh and Gilreath's (1986) findings, where increased storage time decreased the amount of time to shoot emergence for the cultivar Cascade Violet Night. The number of weeks needed for shoot emergence for cultivars A16 and A22 did not significantly decrease until after 16 weeks of storage.

Pupation is the phenomenon described when a new, dormant corm or "pupa" develops on the mother corm (De Hertogh and Le Nard, 1993) and occurs during inadequate or improper storage conditions. Pupation is often observed in freesia corms [Freesia hybrida (Aoba, 1974; de Lint, 1969; Gilbertson-Ferriss et al., 1981; Hartsema, 1962)]. In our study, pupation occurred in all cultivars except for A22. Most pupation occurred on rhizomes that received no storage period. Interestingly, rhizomes of cultivar A09 without any storage period did not pupate and also were the rhizomes with the longest time to shoot emergence. It is unclear why rhizomes of certain cultivars pupated while other cultivars did not. Zimmer and Junker (1985) observed pupation in achimenes when the rhizomes were stored at 20 to $25^{\circ} \mathrm{C}$. Lee et al. (2003) reported that pupation in freesia is affected by the temperature conditions in which the stock plants were grown. While this is a possible explanation for some of the pupation observed in this study, the stock plants from which the rhizomes were harvested were all subjected to the same cultural conditions. In this study, the growth and development of pupated rhizomes was no different from the rhizomes that did not pupate, unlike that of freesia, where the newly pupated corm is dormant (De Hertogh and Le Nard, 1993). Although achimenes and freesia are geophytes, a tuberous rhizome and a bulbous corm, respectively, the difference in pupation characteristics may be due to morphology and the related complex physiology.

The results of this study provide more insight into the dormancy of several new achimenes cultivars. It appears that, after senescence, some of the new cultivars do not develop the deep dormancy reported for older cultivars. Moreover, with cultivars tested in this study, optimal rhizome storage was 4 weeks.

Cultivar selection is important to achieve desired market dates. Planting rhizomes too early offers no benefit and increases the risk for pupation in some cultivars. The risk of pests and pathogen attacks may increase if rhizomes remain dormant in pots, complicating production problems. Further research on different storage temperatures on achimenes rhizomes, along with subsequent growth and development would be beneficial.

\section{Literature cited}

Aoba, T. 1974. Effect of temperature on bulb and tuber formation in bulbous and tuberous crops. III. Effect of the heat treatment on the pupa formation in freesia. J. Jpn. Soc. Hort. Sci. 42:341346.

Brickell, C., and J. Zuk (eds.). 1996. A-Z encyclopedia of garden plants. DK Publishing, New York.

De Hertogh, A.A. and M. Le Nard. 1993. General chapter on summer flowering bulbs, p. 741-774. In: A.A. De Hertogh and M. Le Nard (eds.). The physiology of flower bulbs. Elsevier Science, Amsterdam, The Netherlands.

de Lint, P.J.A.L. 1969. Flowering in freesia: Temperature and corms. Acta Hort. 14:125-131.

Gilbertson-Ferriss, T.L., M.L. Brenner, and H.F. Wilkins. 1981. Effects of storage temperatures on endogenous growth substances and shoot emergence in Freesia bybrida corms. J. Amer. Soc. Hort. Sci. 106:455-460.

Harbaugh, B.K. and J.P. Gilreath. 1986. Influence of rhizome harvest date, length of storage and $\mathrm{GA}_{3}$ on sprouting and flowering of achimenes. Proc. Florida State Hort. Soc. 99:237-239.

Hartsema, O.M. 1962. Temperature treatment of freesia tubers. Proc. 16th Intl. Hort. Congr. 5:298-304.

Jungbauer, J. 1977. Eine wunderschöne pflanze, die keener kultivieren will. Gartenbauwissenschaft 26:604-606. 


\section{Research Reports}

Larson, R. (ed.). 1992. Introduction to floriculture. Academic Press, San Diego.

Lee, J.-J., J.-S. Jeong, J.-S. Choi, Y.-R. Kwon, and H.-B. Bark. 2003. Effects of pre-harvest temperature during the induction period of dormancy on growth, dormancy development, and pupation in Freesia bybrida corms. Acta Hort. 620:281-287.

Lyon, L. 1967. Achimenes the magic flower, p. 125-138. In: P. Schulz (ed.). Gesneriads and how to grow them. Diversity Books, Grandview, MO.
Marvinny, C.J. 1967. Gesneriads the florescent way, p. 35-56. In: P. Schulz (ed.) Gesneriads and how to grow them. Diversity Books, Grandview, MO.

Rees, A.R. 1992. Ornamental bulbs, corms, and tubers. CAB International, Wallingford, UK.

Vlahos, J.C. 1985. Effects of BA and $\mathrm{GA}_{3}$ on sprouting of Achimenes rhizomes. Acta Hort. 167:211-224.

Vlahos, J.C. 1991. Growth and development in Achimenes cultivars. Disserta- tion. Wageningen Univ., Wageningen, The Netherlands.

Wiles, L. 1988. Cultural notes: Achimenes. GrowerTalks 15(12):12.

Wilkins, H.F. 2005. Achimenes, p. 253256. In: J. Dole and H.F. Wilkins (eds.). Floriculture: Principles and species. Prentice-Hall, Upper Saddle River, NJ.

Zimmer, K. and K. Junker. 1985. Achimenes, p. 391-392. In: A.H. Halevy (ed.). Handbook of flowering Vol. 1. CRC Press, Boca Raton, FL. 